\title{
Molybdenum Disulfide Quantum Dots Prepared by Bipolar-Electrode Electrochemical Scissoring
}

\author{
Yang Li ${ }^{1}$, Xiaoxia Wang ${ }^{1}$, Mengli Liu ${ }^{1,2}{ }^{,}$Heng Luo $^{3}{ }^{-0}$, Lianwen Deng ${ }^{3}$, Lei Huang ${ }^{2}$, \\ Shuang Wei ${ }^{1}$, Congli Zhou ${ }^{1}$ and Yuanhong $X u^{1,2, *}$ \\ 1 College of Materials Science and Engineering, Qingdao University, Qingdao 266071, China; \\ liyang4875@outlook.com (Y.L.); wxx@qdu.edu.cn (X.W.); 15705420340@163.com (M.L.); \\ 11181011018@stu.ouc.edu.cn (S.W.); 2017021070@qdu.edu.cn (C.Z.) \\ 2 College of Life Sciences, Qingdao University, Qingdao 266071, China; lei_hl@126.com \\ 3 College of Physics and Electronics, Institute of Super-Microstructure and Ultrafast Process in Advanced \\ Materials, Central South University, Changsha 410083, China; luohengcsu@csu.edu.cn (H.L.); \\ denglw@csu.edu.cn (L.D.) \\ * Correspondence: yhxu@qdu.edu.cn; Tel.: +86-532-83780128
}

Received: 11 April 2019; Accepted: 10 June 2019; Published: 21 June 2019

\begin{abstract}
A convenient bipolar-electrode (BPE) electrochemical method was engineered to produce molybdenum disulfide $\left(\mathrm{MoS}_{2}\right)$ quantum dots (QDs) using pure phosphate buffer (PBS) as the electrolyte and the $\mathrm{MoS}_{2}$ powder as the precursor. Meanwhile, the corresponding by-product precipitate was studied, in which $\mathrm{MoS}_{2}$ nanosheets were observed. The BPE design would not be restricted by the shape and size of the $\mathrm{MoS}_{2}$ precursor. It could lead to the defect generation and $2 \mathrm{H} \rightarrow 1 \mathrm{~T}$ phase variation of the $\mathrm{MoS}_{2}$, resulting in the formation of nanosheets and finally the QDs. The as-prepared $\mathrm{MoS}_{2}$ QDs exhibited high photoluminescence (PL) quantum yield of $13.9 \%$ and average lateral size of $4.4 \pm 0.2 \mathrm{~nm}$, respectively. Their excellent PL property, low cytotoxicity, and good aqueous dispersion offer promising applicability in PL staining and cell imaging. Meanwhile, the as-obtained byproduct containing the nanosheets could be used as an effective electromagnetic wave (EMW) absorber. The minimum reflection loss (RL) value was $-54.13 \mathrm{~dB}$ at the thickness of $3.3 \mathrm{~mm}$. The corresponding bandwidth with efficient attenuation $(<-10 \mathrm{~dB})$ was up to $7.04 \mathrm{GHz}$ (8.8-15.84 GHz). The as-obtained EMW performance was far superior over most previously reported $\mathrm{MoS}_{2}$-based nanomaterials.
\end{abstract}

Keywords: molybdenum disulfide; bipolar-electrode; electrochemical method; quantum dots; electromagnetic wave absorption

\section{Introduction}

$\mathrm{MoS}_{2}$ belongs to one two-dimensional (2D) group-VIB transition metal dichalcogenides (TMDs), which has gained significant attention due to their large surface area (SSA), distinct electrical properties and tunable bandgaps [1]. The $\mathrm{MoS}_{2}$ nanomaterials have shown great application potentials in catalysis [2-4], electromagnetic wave (EMW) adsorption [5,6], biomedical applications [6], etc. For example, $\mathrm{MoS}_{2}$ nanosheets were confirmed to be a promising EMW absorber not only because of their high SSA, but also due to the defect dipole polarization resulting from Mo and S vacancies as well as the phase transition between the trigonal prismatic $(2 \mathrm{H})$ semiconducting phase to octahedral (1T) metallic one [7-10]. It has an indirect band gap of $1.2 \mathrm{eV}$ in its bulk form, while becomes $1.9 \mathrm{eV}$ when thinned to the monolayer nanosheets, indicating the formation of a direct band-gap semiconductor [2,11,12]. Furthermore, PL could emerge when the thickness of $\mathrm{MoS}_{2}$ crystals became smaller [12]. Besides the layer number, the nanoscale size of the $\mathrm{MoS}_{2}$ would also contribute 
to the PL emission due to the edge effects and quantum confinement [2]. As a result, PL MoS quantum dots (QDs) could be obtained. Many approaches have been proposed to synthesize the $\mathrm{MoS}_{2}$ QDs including the electro-Fenton processing [8], Li-intercalation [13,14], ultrasonication [15,16], hydrothermal/solvothermal treatment, and CVD approaches [17]. Despite the achievements, they are still restricted by the time consumption, or poor environmental tolerance, or expensive instrument or hazardous organic solvents [8]. Therefore, there is a great need to discover a simple, efficient, non-toxic, and cost-effective method for preparing $\mathrm{MoS}_{2}$ nanomaterials.

The electrochemical method has been widely used in exfoliating the 2D materials due to its superiorities including simple operation, low consumption, good reproducibility [8], etc. Applications of the traditional electrochemical methods in preparing $\mathrm{MoS}_{2}$ QDs have also been explored [17, 18]. Therein, precursor in bulky form have to be applied as the working electrodes (or anodes). However, the $\mathrm{MoS}_{2}$ precursor popularly exists in the form of powder, which greatly limits its wide application in the preparation of $\mathrm{MoS}_{2}$ QDs.

Bipolar-electrode (BPE) method is a special type of electrochemical method that has attracted much attention recently. Its device is mainly connected to a driving power source (such as the $\mathrm{Pt}$ electrode, Au electrode, etc.) and a conductor immersed in the electrolyte (i.e., bipolar electrode, BPE) composition. A BPE can act as an anode and a cathode at the same time, on which the oxidation and reduction reactions occur at the respective end. This method has the advantages of simplicity, easy operation, and especially not limited by the shape of the precursor conductor [18]. Accordingly, large-size conductive 2D materials such as black phosphorus [19] and $\mathrm{WS}_{2}$ [20] can be electrolyzed into nano-sized particles, despite the precursor is in bulky form or powder. However, as far as we know, there is no report about the preparation of the QDs derived from the 2D materials via the BPE methods, not to mention the $\mathrm{MoS}_{2}$ QDs. In addition, upon the BPE treatment for the 2D materials, only the nano-sized particles were paid close attention, while the by-product precipitate has been neglected, which might provide useful information for elucidating the BPE process and hold great application potential.

In this study, the BPE electrochemical strategy was applied for preparing $\mathrm{MoS}_{2}$ QDs using the $\mathrm{MoS}_{2}$ powder and PBS as the precursor and electrolyte, respectively. Meanwhile, the corresponding by-product precipitate was also studied, in which the $\mathrm{MoS}_{2}$ nanosheets were obtained. The electrochemical process was not restricted with the shape of the $\mathrm{MoS}_{2}$ precursor. It showed the advantages of simplicity and environmental friendliness. The as-prepared $\mathrm{MoS}_{2}$ QDs exhibit good PL, high crystallinity, good dispersion, and narrow particle size distribution. Their advantages offer promising applicability in PL staining and cell imaging. The as-obtained precipitate containing the nanosheets was also tested for the EMW absorption. Through the various characterizations, we proposed the generation mechanism of the $\mathrm{MoS}_{2}$ QDs and nanosheets via the BPE electrochemical strategy.

\section{Materials and Methods}

Reagents: Bulk $\mathrm{MoS}_{2}$ powder (mol wt 160.07, purity 98.0\%), sodium dihydrogen phosphate dehydrate (mol wt 156.01, purity 99.0\%), disodium hydrogen phosphate dodecahydrate (mol wt 358.14, purity $99.0 \%$ ), sodium hydroxide (granular, mol wt 40, purity $96.0 \%$ ), ethanol (mol wt 46.07, purity 99.7\%), and potassium bromide (mol wt 119, purity 99.0\%) was supplied by Sinopharm Chemical Reagent Co., Ltd., Shanghai, China. Ammonium fluoride $\left(\mathrm{NH}_{4} \mathrm{~F}, \mathrm{~mol} w \mathrm{t}\right.$ 37.04, purity $\geq 96 \%$ ), concentrated sulfuric acid $\left(\mathrm{H}_{2} \mathrm{SO}_{4}\right.$, mol wt 98.04 , density $\left.1.84 \mathrm{~g} \mathrm{~cm}^{-3}\right)$. 3-(4,5-dimethyl-2-thiazolyl)-2,5-diphenyltetrazolium bromide (MTT, mol wt 414.32, purity 98\%), lysogeny broth (LB) medium, Dulbecco's modified Eagle medium (DMEM). All other reagents were of analytical grade and applied as received. Deionized distilled water was applied in the experiment.

Apparatus: The RXN-305D DC power supply was obtained from Shenzhen Zhaoxin Yuan Electronics Co., Ltd. (Shenzhen, China). The LCD numerical controlled heating type magnetic stirrer, model MS-H-Pro+, is provided by Dragon Laboratory Limited (Beijing, China). The high-speed table centrifuge model of TGL-15B was provided by Shanghai anting scientific instrument factory. 
The morphology of $\mathrm{MoS}_{2}$ QDs was observed on a JEOL Ltd. JEM-2010 transmission electron microscope (JEOL Ltd., Beijing, China) and atomic force microscopy using a SPI3800N microscope operating in the tapping mode (Seiko Instruments Inc., Shenzhen, China). The XRD was carried out on a Rigaku D-MAX 2500/PC with the Cu K $\alpha$ radiation $(\lambda=1.54056 \AA$ ) (Tokyo, Japan). FTIR was carried out on a Nicolet 5700 FTIR spectrometer (Thermo Electron Scientific Instruments Corp., Shanghai, China). The Raman spectra were performed using a DXR2 micro Raman imaging spectrometer (Thermo Fisher, Waltham, MA, U.S). XPS data were collected on an ESCALab220i-XL electron spectrometer (VG Scientific, West Sussex, U.K.) using $300 \mathrm{~W}$ Al K $\alpha$ radiation. The FL spectra were performed on an Edinburgh instruments spectrofluorometer FS5 (Edinburgh, U.K.) with the excitation/emission slits of $5.0 \times 5.0 \mathrm{~nm}$. The ultraviolet-visible (UV-vis) absorbance was gained from a Mapada UV-6300 double beam spectrophotometer (Shanghai, China). The electromagnetic parameters were evaluated by an Agilent AV3618 vector network analyzer.

Preparation of $\mathrm{MoS}_{2}$ QDs and precipitate containing the nanosheets: The $\mathrm{MoS}_{2}$ QDs and precipitate containing the nanosheets were synthesized by a low cytotoxicity, simple, and nondestructive BPE electrochemical system. Typically, PBS $(0.2 \mathrm{M}, \mathrm{pH}=7.4)$ was used as the electrolyte solution, and $\mathrm{MoS}_{2}$ powder $(0.173 \mathrm{~g})$ was placed in a beaker $(50 \mathrm{~mL})$. Two platinum $(\mathrm{Pt})$ sheets (area $>1.0 \mathrm{~cm}^{2}$ ) were used as the anode and the cathode, respectively. Different electrolyte compositions all at 0.2 $\mathrm{M}\left(\mathrm{PBS}, \mathrm{NH}_{4} \mathrm{~F}\right.$, and $\left.\mathrm{H}_{2} \mathrm{SO}_{4}\right)$, applied voltages $(3 \mathrm{~V}, 5 \mathrm{~V}$, and $7 \mathrm{~V})$ and reaction times $(0-30 \mathrm{~h})$ were optimized for the preparation. The electrochemical exfoliation was conducted accompanying with stirring at $500 \mathrm{rpm}$ for the whole experiment. The above-mentioned reaction solution was under centrifugation at 12,000 rpm for 15 min to reach a colorless dispersion containing $\mathrm{MoS}_{2}$ QDs and grey-black precipitation, respectively. The colorless dispersion was dialyzed in a 1000 Da dialysis bag against deionized water for $12 \mathrm{~h}$ to remove phosphate and obtain purified $\mathrm{MoS}_{2}$ QDs. The grey-black precipitates are dried by freeze-drying to for further characterization and applications.

\section{Results and Discussion}

\subsection{Preparation and Characterization of the $M_{0} S_{2}$ QDs and Precipitate Containing the Nanosheets}

As shown in Scheme 1, MoS 2 QDs and nanosheets were prepared through a simple BPE electrochemical system using $\mathrm{MoS}_{2}$ powder as the precursor. The products were finally centrifuged to collect the supernatant and precipitate, respectively. Different applied voltages and reaction times electrolyte compositions were tested for the preparation. Bubbles were observed on the platinum electrodes during electrolysis, indicating the possible evolution of oxygen and hydrogen due to the electrolysis of water. As shown in Figure S1, the $\mathrm{MoS}_{2}$ QDs can be obtained at different experimental conditions, indicating the universality of the BPE synthesis strategy. Furthermore, the PL quantum yield of the as-prepared $\mathrm{MoS}_{2}$ QDs was evaluated based on the method indicated in the Supporting Information [21-26]. However, too low applied voltage (e.g., $3 \mathrm{~V}$ ) would result in too low of an exfoliation efficiency, thus resulting in too long of a process. While too high voltage (e.g., $7 \mathrm{~V}$ ) would lead to high current in the BPE system. In addition, bubbles generation on the platinum electrodes would be accelerated at higher applied voltage. Both the higher current and more generated bubbles would cause faster loss of the water, leading to unstable composition of the reaction system. Accordingly, $5 \mathrm{~V}$ was chosen as the optimized applied voltage. Meanwhile, it was found that the PL quantum yield of the $\mathrm{MoS}_{2}$ QDs increased with the increasing electrolysis time from 0 to $20 \mathrm{~h}$, while longer time than $20 \mathrm{~h}$ would not only offer little positive effect on the quantum yield but also lead to great loss of the water. Thus, $20 \mathrm{~h}$ was selected as the optimum reaction time. Meanwhile, the PBS $(\mathrm{pH}=7.4)$ showed the highest PL quantum yield among the tested electrolytes under the same applied voltage and reaction time. As a result, the optimum conditions were set as follows: applied voltage: $5 \mathrm{~V}$, reaction time: $20 \mathrm{~h}$ and electrolyte: $0.2 \mathrm{M} \mathrm{PBS}$ ( $\mathrm{pH} 7.4$ ), which was used for the further experiments. The highest PL quantum yield of the as-prepared $\mathrm{MoS}_{2}$ QDs was calculated to be $13.9 \%$. 


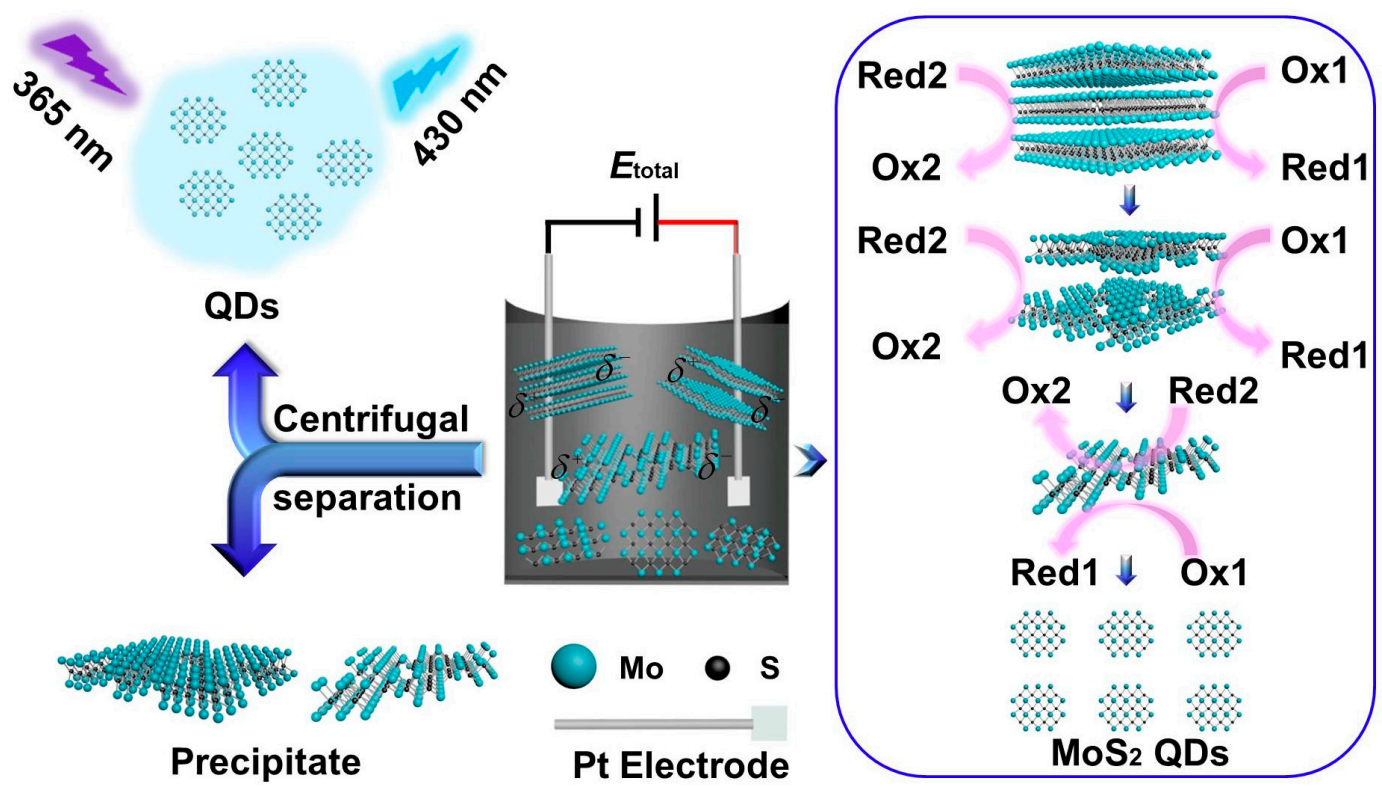

Scheme 1. Scheme of the preparation of $\mathrm{MoS}_{2}$ QDs and $\mathrm{MoS}_{2}$ precipitate by a BPE electrochemical method in the PBS.

The optical features of the as-prepared $\mathrm{MoS}_{2}$ QDs (0.2 M PBS, $5 \mathrm{~V}, 20 \mathrm{~h}$ ) were studied by the UV-vis absorption and the PL spectroscopy accordingly. As shown, distinct absorption peaks at $221 \mathrm{~nm}$ was observed in the UV-vis absorption (Figure 1A), which should be ascribed to the excitonic characteristics of the $\mathrm{MoS}_{2}$ QDs [21-23]. Meanwhile, the 1931 CIE chromaticity diagram of the $\mathrm{MoS}_{2}$ QDs (Figure 1B) shows that the PL was in the blue emission region $(0.14,0.05)$ upon the excitation wavelength at $310 \mathrm{~nm}$, which well matched with the UV-vis adsorption result. The PL of $\mathrm{MoS}_{2}$ QDs was collected upon different excitation wavelengths between 300 and $370 \mathrm{~nm}$ (Figure 1C). The emission spectra changed from 420 to $466 \mathrm{~nm}(2.66-2.95 \mathrm{eV})$ accordingly. As illustrated in Figure 1A, the maximum emission was obtained at $420 \mathrm{~nm}(2.95 \mathrm{eV})$ under the excitation wavelength at $310 \mathrm{~nm}(4 \mathrm{eV})$. The excitation-dependent PL emission is consistent with previous reports of the $\mathrm{MoS}_{2}$ QDs $[8,24,25]$. The PL decay curve of $\mathrm{MoS}_{2}$ QDs is shown in Figure 1D. The curve was fitted with a biexponential function, showing two dominant excitonic processes with nanosecond luminescence lifetime. Two excitonic lifetime of $1.25 \mathrm{~ns}$ (ca. $30.81 \%$ ) and $5.57 \mathrm{~ns}$ (ca. 69.19\%) can be obtained, respectively. In addition, the average PL lifetime of the as-prepared $\mathrm{MoS}_{2}$ QDs was estimated to be $4.24 \mathrm{~ns}$.

In Figure 2A, the typical TEM image of the supernatant showed mono-dispersed nanodots, showing the possible formation of the $\mathrm{MoS}_{2}$ QDs with good dispersion in the aqueous medium. The nanodots were highly uniform with the average dimension of $4.4 \pm 0.3 \mathrm{~nm}$ (Figure 2B). The illustration in Figure 2A is a high-resolution TEM (HRTEM) image of $\mathrm{MoS}_{2}$ QDs. The corresponding lattice spacing at $0.19 \mathrm{~nm}$ corresponds to the (100) plane, which was consistent with the reported values (JCPDS: 37-1492). The atomic force microscopy (AFM) image was also collected for the $\mathrm{MoS}_{2}$ QDs (Figure 2C). Besides the further confirmation of the good-dispersibility, the corresponding height analysis indicated that the thickness of the $\mathrm{MoS}_{2}$ QDs was between 1.95 and $2.0 \mathrm{~nm}$ and $1.98 \pm 0.02 \mathrm{~nm}$ in average (the inset of Figure 2C), suggesting that the $\mathrm{MoS}_{2}$ QDs were highly exfoliated and in few layer [27-29].

To study the generation process of the $\mathrm{MoS}_{2}$ QDs, the TEM characterization were also carried out for the precipitate generated at electrolysis times of 5, 10, 15, and $20 \mathrm{~h}$, respectively. As shown, compared with the $\mathrm{MoS}_{2}$ precursor form (Figure 2D), electrolysis time of $5 \mathrm{~h}$ (Figure 2E) does not affect the morphology of $\mathrm{MoS}_{2}$ sheets. With the reaction time extended to $10 \mathrm{~h}, \mathrm{MoS}_{2}$ sheets with smaller thickness and smaller lateral dimension (95.8-231.6 nm) can be observed (Figure 2F). With the ongoing reaction to $15 \mathrm{~h}$, much smaller nanosheets ranging from $11.2 \mathrm{~nm}$ to $61.4 \mathrm{~nm}$ appeared on the surface of the $\mathrm{MoS}_{2}$ sheets (Figure 2G). Subsequently, the nanosheets could be completely separated from the $\mathrm{MoS}_{2}$ sheets (Figure 2H) accompanying with the formation of nanodots on the independent nanosheets 
(Figure 2I) at $20 \mathrm{~h}$. Meanwhile, independent nanodots-i.e., $\mathrm{MoS}_{2}$ QDs—could be reached since they were well dispersed in the aqueous supernatant (Figure 2A) [30].
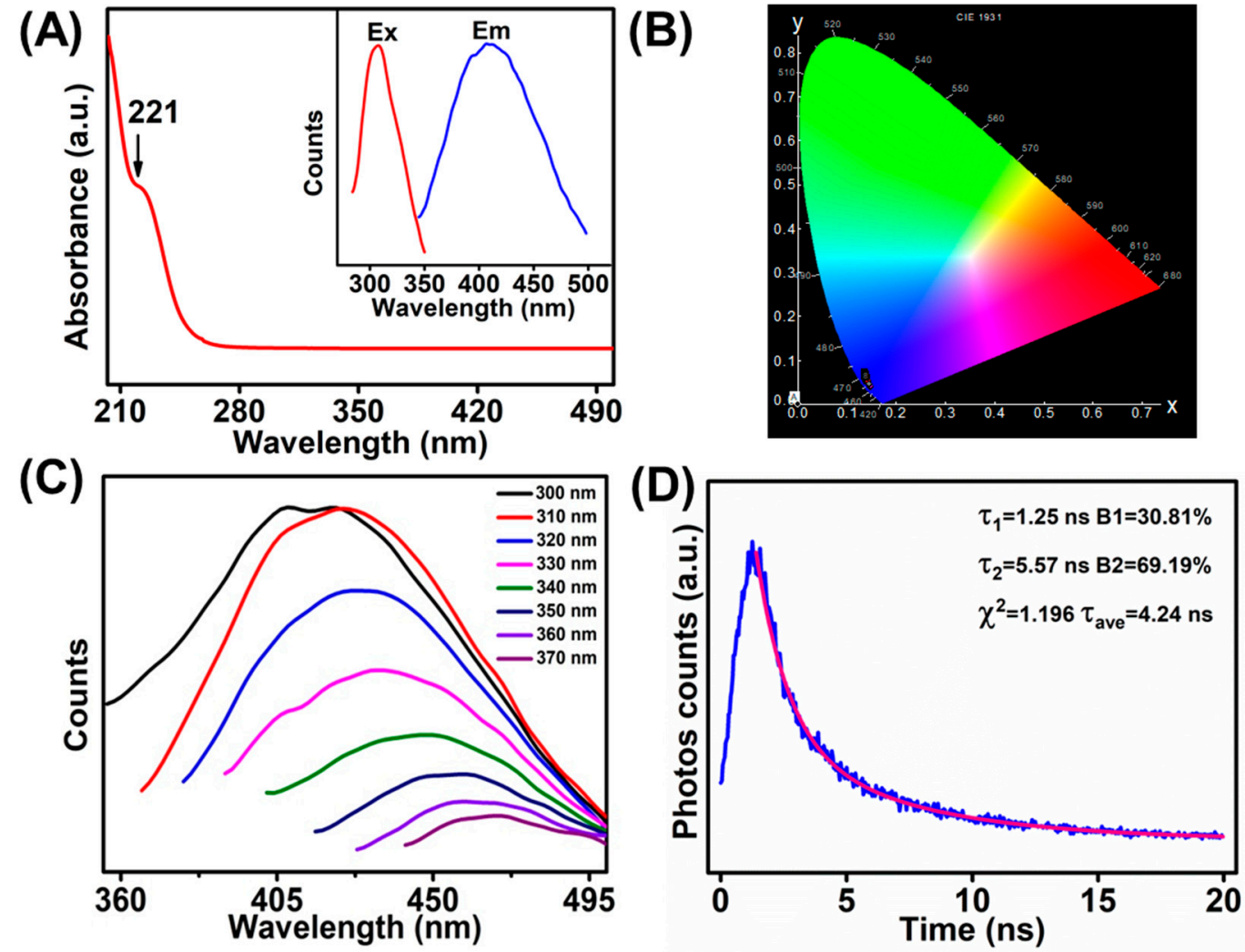

Figure 1. (A) UV-vis absorption spectrum of $\mathrm{MoS}_{2}$ QDs (inset: PL excitation spectrum and PL emission spectrum). (B) The CIE 1931 chromaticity chart of the $\mathrm{MoS}_{2}$ QDs at excitation of the $310 \mathrm{~nm}$. (C) PL emission spectra of $\mathrm{MoS}_{2}$ QDs with various excitation wavelengths. (D) PL decay curve of MoS 2 QDs.

XRD patterns of the $\mathrm{MoS}_{2}$ QDs and the precipitate generated at $20 \mathrm{~h}$ were then investigated while using that of the $\mathrm{MoS}_{2}$ precursor for comparison. The precursor shows an intensive diffraction peak at $2 \theta=14.4^{\circ}$ and four weaker peaks at $2 \theta=29.026^{\circ}, 32.68^{\circ}, 39.54^{\circ}$, and $49.79^{\circ}$, respectively (curve a in Figure 3A). These signals were ascribed to the (002), (004), (100), (103), and (105) lattice planes of $\mathrm{MoS}_{2}$, respectively. Other weaker peaks are also characteristic peaks of $\mathrm{MoS}_{2}$ precursor. While for the precipitate (curve $b$ in Figure 3A), all the other characteristic peaks of $\mathrm{MoS}_{2}$ were maintained except for the $29.026^{\circ}(004)$ peaks. The disappearance of pristine (004) planes suggested the possible variation of $\mathrm{MoS}_{2}$ from $2 \mathrm{H}$ to metallic $1 \mathrm{~T}$ phase [31]. The formation of a bulge between $16.09^{\circ}$ to $31.5^{\circ}$ should be due to the deterioration of the crystallization of the $\mathrm{MoS}_{2}$ precipitate [32]. While for the $\mathrm{MoS}_{2}$ QDs (curve c in Figure 3A), most of the other peaks were disappeared due to their highly exfoliated structure. Only two peaks could be observed at $2 \theta=14.4^{\circ}(002)$ and $32.68^{\circ}(100)$, respectively. Furthermore, the obvious signal decrease of the (002) indicates the formation of $\mathrm{MoS}_{2}$ QDs in a few layers. The surface functional groups on $\mathrm{MoS}_{2}$ QDs and precipitate were studied through the Fourier transform infrared (FTIR) (Figure 3B). As shown, the $\mathrm{MoS}_{2}$ precursor and precipitate have similar absorption peaks, indicating their similar surface chemistry. While for $\mathrm{MoS}_{2}$ QDs, the peaks at 3449, 952,898 , and $465 \mathrm{~cm}^{-1}$ should be attributed to the stretching vibration of $\mathrm{C}-\mathrm{OH}, \mathrm{Mo}=\mathrm{O}, \mathrm{S}-\mathrm{OH}$, and Mo-S, respectively [22,24,33]. Also, the vibrational absorption of $\mathrm{C}=\mathrm{O}$ at $1600 \mathrm{~cm}^{-1}$ could be observed [22]. However, the Mo-OH bending vibration at $1384 \mathrm{~cm}^{-1}$ and $\mathrm{S}-\mathrm{H}$ at $619 \mathrm{~cm}^{-1}$ disappeared compared with the $\mathrm{MoS}_{2}$ precursor and the precipitate form [33]. It can obtain that the S-OH and $\mathrm{Mo}=\mathrm{O}$ functional groups were generated on the $\mathrm{MoS}_{2}$ QDs surface, suggesting that the $\mathrm{MoS}_{2}$ QDs are slightly oxidized. Raman spectroscopy was further applied to understand the chemical bonding of the 
products. Generally, these peak position shifts in Raman spectroscopy can be used to recognize the layer thicknesses of the 2D layer material [34]. The Raman spectra of $\mathrm{MoS}_{2}$ precursor showed two distinct characteristic peaks being ascribed to the high energy in-plane vibration $\mathrm{A}_{1 \mathrm{~g}}$ at $405.2 \mathrm{~cm}^{-1}$ and the lower energy out-of-plane vibration $\mathrm{E}^{1}{ }_{2 \mathrm{~g}}$ at $378 \mathrm{~cm}^{-1}$ (curve a in Figure $3 \mathrm{C}$ ) [35,36]. The position of the $E^{1}{ }_{2 g}$ and $A_{1 g}$ peak in the $M_{2} S_{2}$ precipitate (curve $b$ in Figure $3 C$ ) shows that the intrinsic hexagonal lattices in $\mathrm{MoS}_{2}$ were still maintained. While the $\mathrm{E}_{2 \mathrm{~g}}^{1}$ and $\mathrm{A}_{1 \mathrm{~g}}$ modes in the precipitates showed red and blue shifts, respectively, compared with those of $\mathrm{MoS}_{2}$ precursor. Accordingly, the position difference value between the two modes changed from $27.2 \mathrm{~cm}^{-1}$ to $25.9 \mathrm{~cm}^{-1}$. Accordingly, it is speculated that the $\mathrm{MoS}_{2}$ layered structure was destroyed during the electrolysis process, resulting in the reduced $\mathrm{MoS}_{2}$ layers, smaller sizes, and more defects, which were consistent with previously reported results $[37,38]$. Meanwhile, blue shifts of $A_{1 g}$ mode (curve $c$ in Figure $3 C$ ), reduced frequency difference between $\mathrm{E}^{1}{ }_{2 \mathrm{~g}}$ and $\mathrm{A}_{1 \mathrm{~g}}$ modes $\left(22.2 \mathrm{~cm}^{-1}\right)$ and more abundant Raman peaks were observed for the $\mathrm{MoS}_{2}$ QDs than those for both the precursor and precipitate [37,38]. Therein, the abundant peaks should be attributed to the defects generated at the surfaces and edges of the $\mathrm{MoS}_{2}$ QDs, which are significant factor for the corresponding FL emission [37,39].
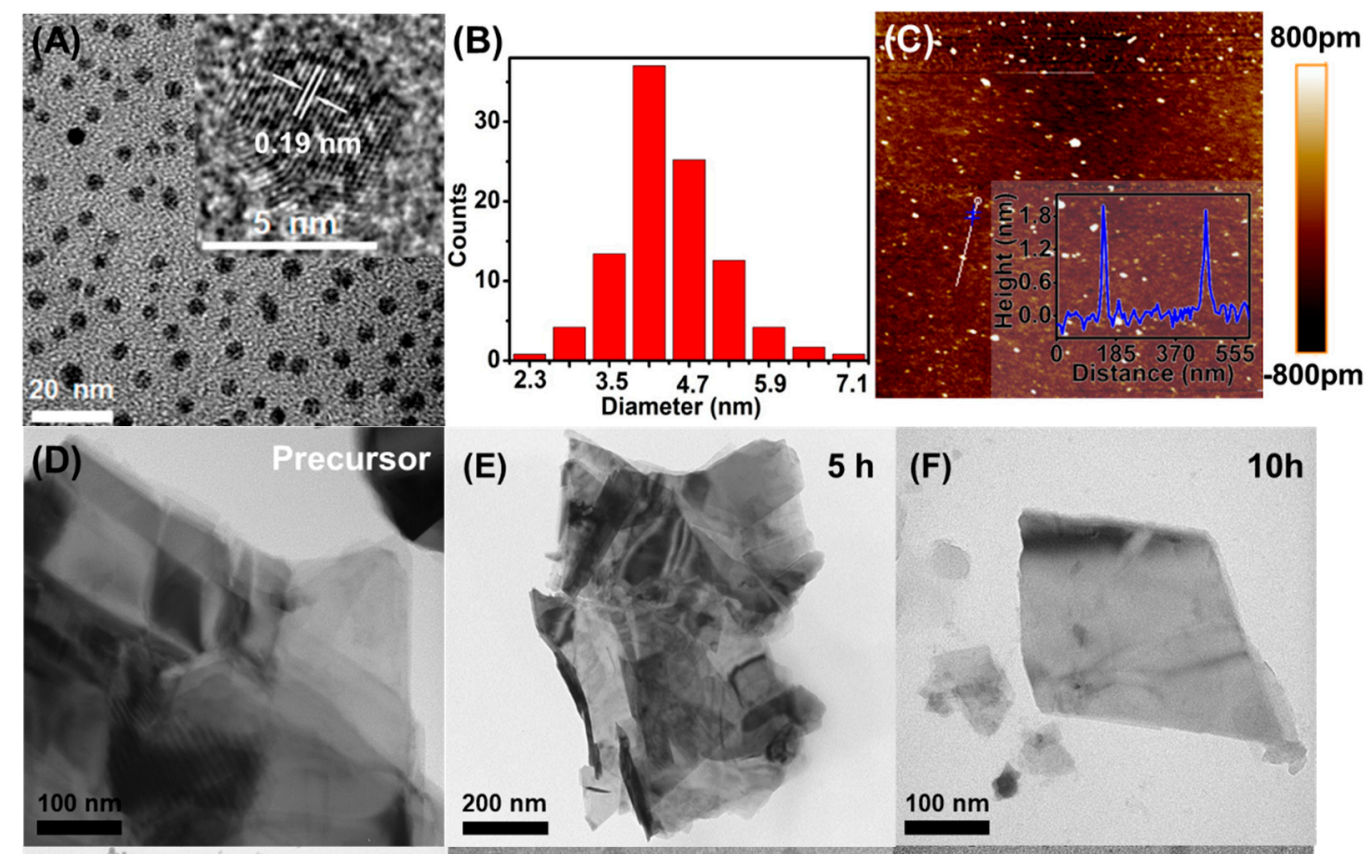

$5 \mathrm{~h}(\mathrm{~F})$

$10 \mathrm{~h}$
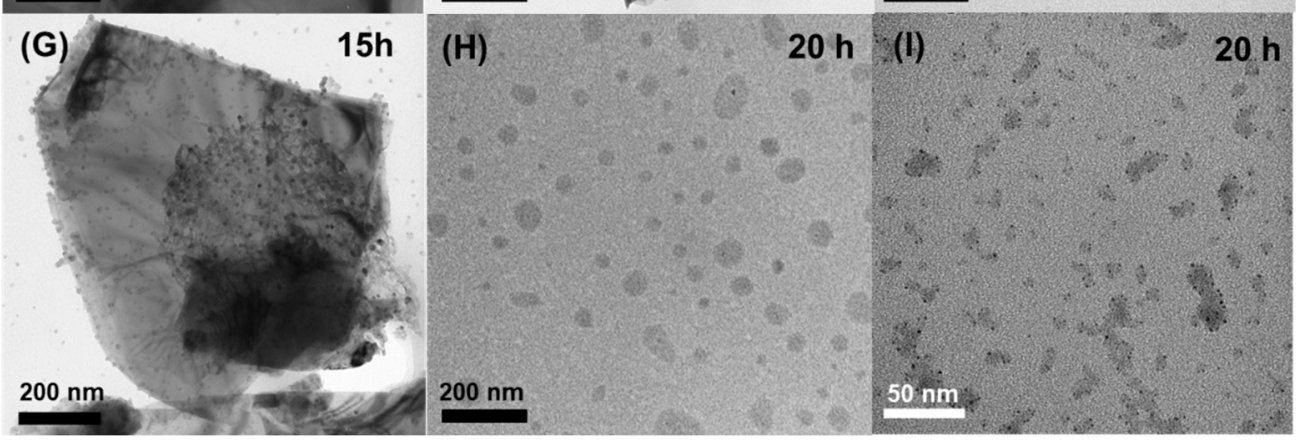

Figure 2. (A) TEM images (inset: HRTEM image), (B) particle size distribution, and (C) AFM image (inset: height profile) of the $\mathrm{MoS}_{2}$ QDs. TEM images of the $\mathrm{MoS}_{2}$ (D) precursor and (E-I) electrolysis precipitate upon different electrolysis time at 5, 10, 15, $20 \mathrm{~h}$, respectively. 

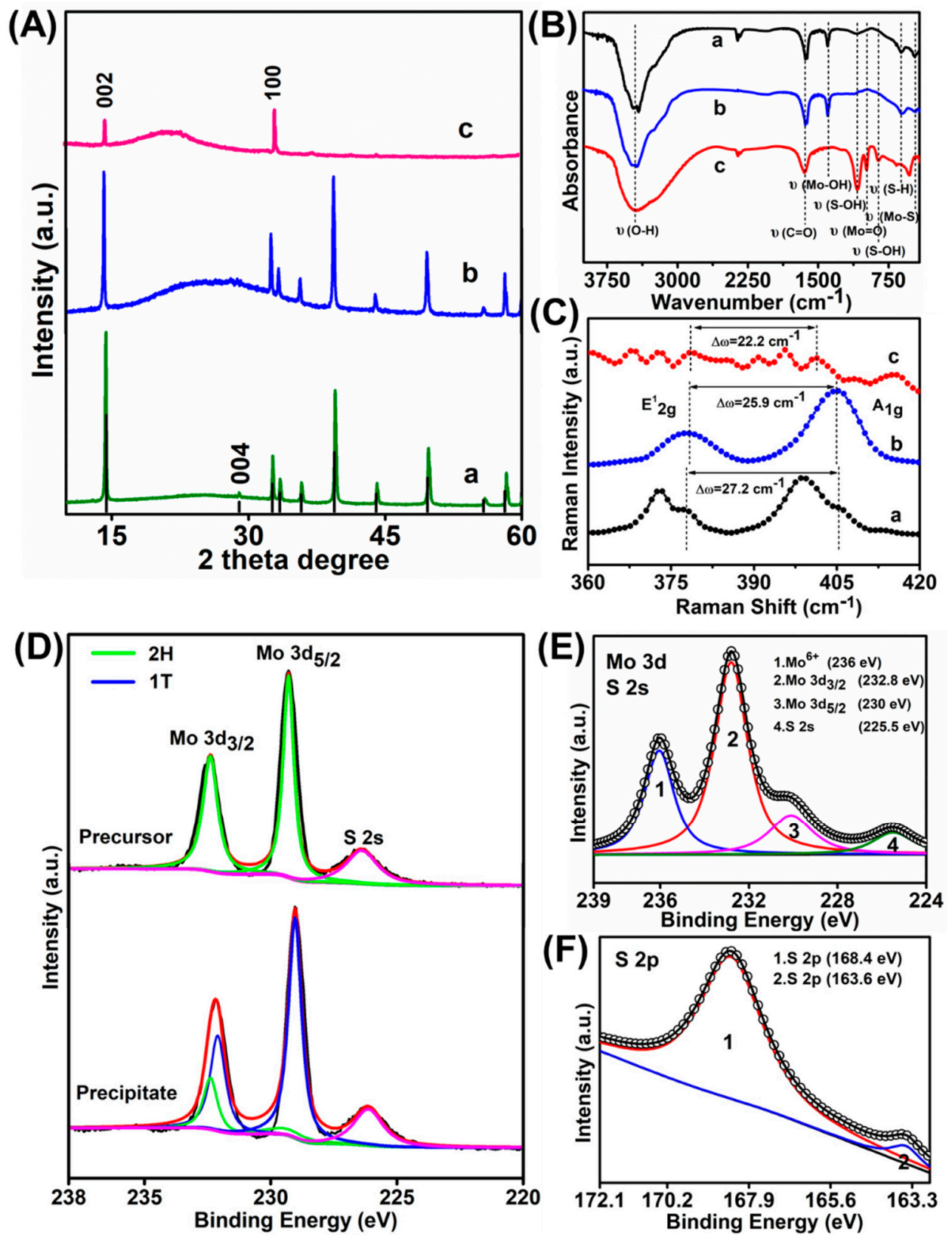

Figure 3. (A) XRD patterns, (B) FTIR spectra, and (C) Raman spectra of a) $\mathrm{MoS}_{2}$ precursor, b) $\mathrm{MoS}_{2}$ precipitate, c) $\mathrm{MoS}_{2}$ QDs, respectively. XPS spectra of the $\mathrm{MoS}_{2}$ samples: (D) narrow scan spectra of Mo 3d of the $\mathrm{MoS}_{2}$ precursor (above) and the precipitate (below), respectively. (E) Mo 3d and (F) S 2p peak of the $\mathrm{MoS}_{2}$ QDs.

X-ray photoelectron spectroscopy (XPS) was further measured to study the elemental composition and surface state of the as-obtained $\mathrm{MoS}_{2}$ samples. As observed, the $\mathrm{MoS}_{2}$ precursor (above curve in Figure 3D) showed its $2 \mathrm{H}$-phase based on the Mo $3 \mathrm{~d}_{5 / 2}$ and Mo $3 \mathrm{~d}_{3 / 2}$ orbitals at $229.3 \mathrm{eV}$ and $232.4 \mathrm{eV}$, as well as the $S 2 p_{3 / 2}$ at $161.4 \mathrm{eV}$ and the $\mathrm{S} 2 \mathrm{p}_{1 / 2}$ orbital at $162.5 \mathrm{eV}$ (Figure S2), respectively. Compared with the precursor, an obvious red shift of Mo $3 d_{5 / 2}$ and Mo $3 d_{3 / 2}$ orbitals was obtained for the $\mathrm{MoS}_{2}$ precipitate (below curve in Figure 3D) and the newly appearing peaks at $229 \mathrm{eV}$ (blue line of Mo $3 \mathrm{~d}_{5 / 2}$ ) and $231.1 \mathrm{eV}$ (blue curve of $\mathrm{Mo} 3 \mathrm{~d}_{3 / 2}$ ) are resulted from the $1 \mathrm{~T}$ phase of $\mathrm{MoS}_{2}$ [5b]. Similarly, the newly emerging peaks at $161.8 \mathrm{eV}$ (blue line of $S 2 \mathrm{p}_{3 / 2}$ ) and $163.1 \mathrm{eV}$ (blue curve of $S 2 \mathrm{p}_{1 / 2}$ ) were observed in the S 2p spectra, which again indicated the presence of $1 \mathrm{~T}$ phase in the $\mathrm{MoS}_{2}$ precipitate (Figure S2) [2,40]. The results of the phase transformation in the as-obtained precipitates through the 
XPS analysis were consistent with the XRD results. Accordingly, it is concluded that the alteration of $\mathrm{MoS}_{2}$ from $2 \mathrm{H}$ to $1 \mathrm{~T}$ phase indeed occurred during the electrolysis process. In addition, the precipitates were mixed with $\mathrm{MoS}_{2}$ in both two phases. The XPS spectra of the $\mathrm{MoS}_{2}$ QDs in the Mo 3d region which could be divided into four peaks (Figure 3E). Therein, the two intense peaks at 232.8 and 230.0 $\mathrm{eV}$ being ascribed to Mo $3 \mathrm{~d}_{3 / 2}$ and Mo $3 \mathrm{~d}_{5 / 2}$, respectively, should be due to the $\mathrm{Mo}^{4+}$ in the $\mathrm{MoS}_{2}$ QDs [8,11,41]. The one at $225.5 \mathrm{eV}$ corresponds to the $\mathrm{S} 2 \mathrm{~s}$ of $\mathrm{MoS}_{2}$ QDs [8,42]. The minor peak locating at $236.0 \mathrm{eV}$ should be due to the $\mathrm{Mo}^{6+}$, which corresponds to the slight oxidation of Mo edges of the $\mathrm{MoS}_{2}$ upon the exfoliation process [13]. The formation of $\mathrm{Mo}=\mathrm{O}$ bonds was consistent with the FTIR spectrum (Figure 3B). Meanwhile, the high-resolution S 2p peaks at 168.4 and $163.6 \mathrm{eV}$ represent were ascribed to the sulfide (Figure 3F) [43].

On the basis of the above-mentioned characterizations, the formation mechanism of the $\mathrm{MoS}_{2}$ QDs and nanosheets based on the BPE strategy can be proposed as follows: two platinum sheets act as the driving electrode in the BPE system, and the $\mathrm{MoS}_{2}$ powder was used as the conductors. When the drive voltage $\left(E_{\text {total }}\right)$ of the $5 \mathrm{~V}$ was applied on the Pt electrodes, the electrochemical reaction can occur in the solution near both ends of $\mathrm{MoS}_{2}$, although there is no direct contact between the Pt electrode and the $\mathrm{MoS}_{2}$. The voltage provided by a DC power supply forms an electric field between the cathode and the anode, and the conductor in the electric field (i.e., $\mathrm{MoS}_{2}$ ) produces a polarization potential $(\delta)$ due to the existence of the electric field. The terminal of the conductor near the driving anode (i.e., the part opposite the anode of the DC power supply in the schematic diagram) is negatively charged and become the cathode of BPE. The conductor near the driving cathode (i.e., the opposite to the cathode of the DC power supply in the schematic diagram) is positively charged and becomes the anode of the BPE. The anodic polarization potential $\delta^{+}$and the cathodic one $\delta^{-}$of the BPE drive the occurrence of electrochemical reactions on the BPE to produce electric current. The total current flowing through the BPE system is divided into two parts: one part flows into the electrolyte solution and one part flows through the suspension of $\mathrm{MoS}_{2}$ precursor, which supplied as countless conductors in the BPE systems. It is due to the current flowing through the so-called conductors to cause the electrochemical exfoliation of bulk $\mathrm{MoS}_{2}$ to firstly sheets in fewer layers and smaller sizes as well as more defects and phase variation, and then to nanosheets, and finally to the nanodots. Bubbles were observed on the platinum electrodes during electrolysis, indicating the possible evolution of oxygen and hydrogen, which should be favorable for the scissoring of the bulk $\mathrm{MoS}_{2}$ to smaller nanosheets and QDs [20]. The as-obtained nanodots could further enhance the formation of the defects and phase transformation of the $\mathrm{MoS}_{2}$ and so forth, the longer the electrochemical stripping time of QDs and nanosheets, the higher the yield.

To further elucidate the novelty of this work, comparison of the previous works with the present one has been added in Table S1 in the Supporting Information [8,13,24,44-46]. As indicated, the present work possesses comparable or superiority such as high quantum yield, simple, convenience, environmental-friendliness, etc.

\subsection{Applications of the As-Obtained $M_{0} S_{2} Q D s$}

Cotton fibers were dyed with $\mathrm{MoS}_{2}$ QDs aqueous suspension, washed by deionized water, and then dried at $50{ }^{\circ} \mathrm{C}$ in the air and finally observed by the inverted fluorescence microscope. As can be seen in Figure S3, the $\mathrm{MoS}_{2}$ QDs showed well excitation wavelength-dependent fluorescence for the stained cotton fibers, which are red, blue and green staining under the exposure of green, UV and blue light irradiation (Figure S3). This result confirmed the great application potential of the as-prepared $\mathrm{MoS}_{2}$ QDs as valuable fluorochromes in bio-/chem- staining.

Due to the intrisic biocompatiblity of the $\mathrm{MoS}_{2}$, the as-prepared $\mathrm{MoS}_{2}$ QDs were tested in the bioimaging taking bamboo fiber cells as representatives. Images were collected by laser scanning confocal microscopy (LSCM) after incubation of $5 \% \mathrm{CO}_{2}$ with $\mathrm{MoS}_{2} \mathrm{QD}$ for $4 \mathrm{~h}$ at $37^{\circ} \mathrm{C}$. More information in detail was presented in the Supporting Information. As indicated in Figure $4 \mathrm{~A}$, the cells incubated with $\mathrm{MoS}_{2}$ QDs exhibited distinct blue PL upon irradiation with a $365 \mathrm{~nm}$ excitation light. Due to the small size $(<5 \mathrm{~nm})$ of the $\mathrm{MoS}_{2}$ QDs, it is easily taken up by cells, enabling efficient bioimaging [47]. 

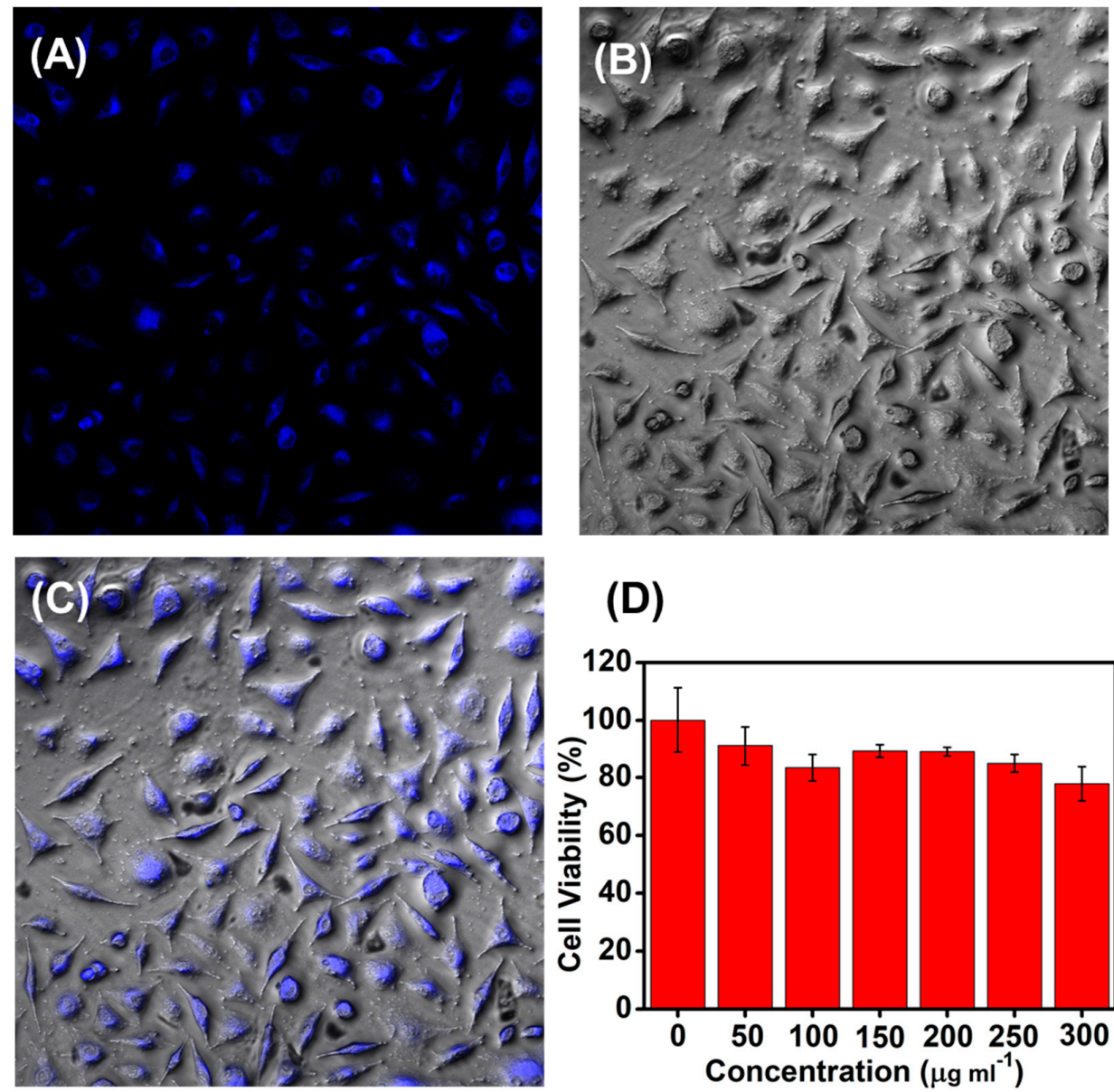

\section{(D)}

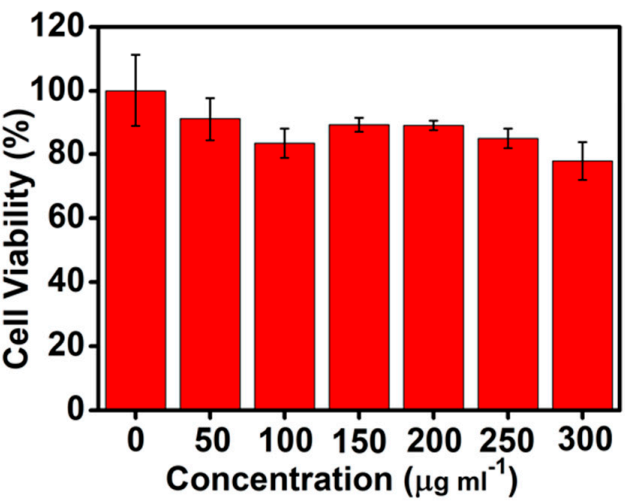

Figure 4. LSCM images of bamboo fiber cells from incubated with $\mathrm{MoS}_{2}$ QDs of $60 \mu \mathrm{g} \mathrm{mL} \mathrm{m}^{-1}$ for 4 $\mathrm{h}$ at $37^{\circ} \mathrm{C}$. (A) PL images and (B) bright field images; Excitation wavelength was set at $365 \mathrm{~nm}$; (C) overlay of (A) and (B). (D) MTT assay of the bamboo fiber cells after being treated with of $\mathrm{MoS}_{2}$ QDs at various concentrations of $0,50,100,150,200,250$, and $300 \mu \mathrm{g} \mathrm{mL}^{-1}$, respectively. The viability of the cells without $\mathrm{MoS}_{2}$ QDs incubation were set as the control (100\%).

The MTT assay was further performed to study the cytotoxicity of the as-obtained $\mathrm{MoS}_{2}$ QDs (Figure 4D). The survival rates slightly went down accompanying with the incremental concentrations of the $\mathrm{MoS}_{2}$ QDs including 0, 50, 100, 150, 200, 250, and $300 \mu \mathrm{g} \mathrm{mL}^{-1}$, respectively. In the culture medium with the maximum tested $\mathrm{MoS}_{2}$ QDs concentration, the cell viability of the cells reached $80 \%$. The good biocompatibility of the as-obtained $\mathrm{MoS}_{2}$ QDs to the cells was confirmed by MTT assay.

\subsection{Application of Precipitate Containing the Nanosheets in EMW Absorption}

As reported, $\mathrm{MoS}_{2}$ nanomaterials with rich defects and good conductivity possess abundant polarization centers and dielectric relaxation, thus leading to conspicuous dielectric loss, and eventually efficient absorption towards the EMW [9]. Through the analysis of the morphology and structure of the $\mathrm{MoS}_{2}$ precipitate as-described above, the precipitate containing the nanosheets with poor crystallinity. This may be caused by a large number of defects before the crystal phase transition occurs. Due to $\mathrm{MoS}_{2}$ QDs are formed on the $\mathrm{MoS}_{2}$ sheets, cavities and defects on the surface and edge of $\mathrm{MoS}_{2}$ precursor were formed, and lots of $\mathrm{MoS}_{2}$ nanosheets were created because of the electrolysis process, so the structure of the $\mathrm{MoS}_{2}$ precursor was destroyed to a certain extent. Therefore, $\mathrm{MoS}_{2}$ precipitate should be a good EMW absorbing material.

To understand the EMW absorption performance of the $\mathrm{MoS}_{2}$ precipitate, electromagnetic parameters of $\mathrm{MoS}_{2}$ precipitate-wax and $\mathrm{MoS}_{2}$ precursor-wax composites with $60 \mathrm{wt} \%$ wax loadings 
were studied in the frequency ranging from 2.0 to $18.0 \mathrm{GHz}$ via the coaxial method. The RL curves of $\mathrm{MoS}_{2}$ precipitate-wax and $\mathrm{MoS}_{2}$ precursor-wax composites were obtained from the measured electromagnetic parameters at a suggested layer thickness and frequency by the transmit line theory that is indicated based on the following equations (Equations (1) and (2)) [48,49]

$$
\begin{gathered}
Z_{\text {in }}=Z_{0}\left(\mu_{\mathrm{r}} / \varepsilon_{\mathrm{r}}\right)^{1 / 2} \tanh \left[j(2 \pi f d l c)\left(\mu_{\mathrm{r}} \varepsilon_{\mathrm{r}}\right)^{1 / 2}\right], \\
\mathrm{RL}=20 \log \left|\left(Z_{\text {in }}-Z_{0}\right) /\left(Z_{\text {in }}+Z_{0}\right)\right|
\end{gathered}
$$

where $\varepsilon_{\mathrm{r}}=\varepsilon^{\prime}-j \varepsilon^{\prime \prime}$ and $\mu_{\mathrm{r}}=\mu^{\prime}-j \mu^{\prime \prime}$ are the relative complex permittivity and permeability of the absorber, respectively, while $Z_{0}$ is the impedance of free space, $c$ is the velocity of light, $f$ is the frequency of microwaves, $Z_{\text {in }}$ and $d$ are the input impedance and the thickness of the absorber, respectively. Considering the weak magnetic properties of $\mathrm{MoS}_{2}, \mu \prime$ and $\mu^{\prime \prime}$ are taken as 1 and 0 , respectively. When RL value is lower than $-10 \mathrm{~dB}, 90 \%$ of EMW energy could be absorbed, implying the materials can be used as practical applications.

Figure 5A shows the RL values and effective absorption bandwidths (the frequency range of $\mathrm{RL} \leq-10 \mathrm{~dB}$ ) of $\mathrm{MoS}_{2}$ precipitate-wax and $\mathrm{MoS}_{2}$ precursor-wax composites at the thicknesses of $3.3 \mathrm{~mm}$. The lowest RL value of $\mathrm{MoS}_{2}$ precipitate-wax could reach $-54.13 \mathrm{~dB}$ at a thickness of $3.3 \mathrm{~mm}$, which was stronger than that of the $\mathrm{MoS}_{2}$ precursor-wax composites. The effective absorption bandwidth of $7.12 \mathrm{GHz}$ and $3.28 \mathrm{GHz}$ of $\mathrm{MoS}_{2}$ precipitate-wax and $\mathrm{MoS}_{2}$ precursor-wax composites were achieved at the thicknesses of $3.3 \mathrm{~mm}$, which means that $\mathrm{MoS}_{2}$ precipitate-wax composites exhibit broader absorption bandwidth than $\mathrm{MoS}_{2}$ precursor-wax composites. Figure $6 \mathrm{~B}$ show the 3D plots of RL with different thickness and frequency of $\mathrm{MoS}_{2}$ precipitate-wax.

(A)
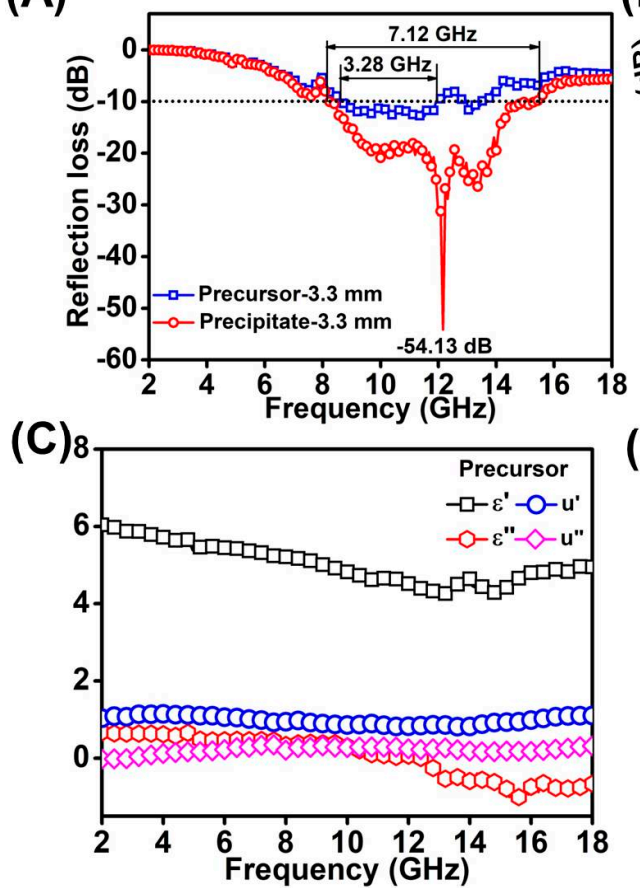

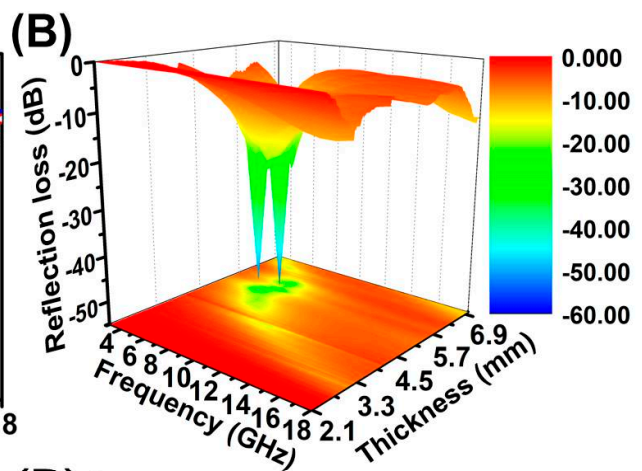

(D)

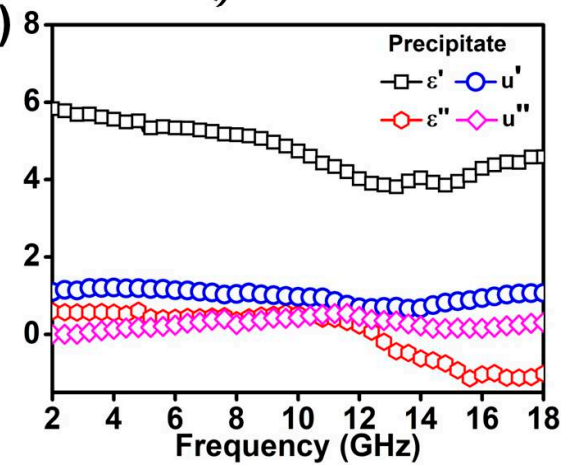

Figure 5. (A) The RL values and effective absorption bandwidths of $\mathrm{MoS}_{2}$ precipitate-wax and $\mathrm{MoS}_{2}$ precursor-wax composites at thicknesses of $3.3 \mathrm{~mm}$ in the range of 2.0-18.0 GHz. (B) 3D RL plots of $\mathrm{MoS}_{2}$ precipitate-wax composites at thicknesses in the range of 2.0-18.0 GHz. The electromagnetic parameters of $\mathrm{MoS}_{2}$ precursor-wax composites (C) and $\mathrm{MoS}_{2}$ precipitate-wax composites (D). 
(A)

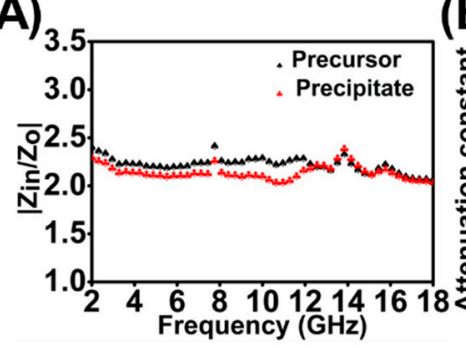

(B)

(C)
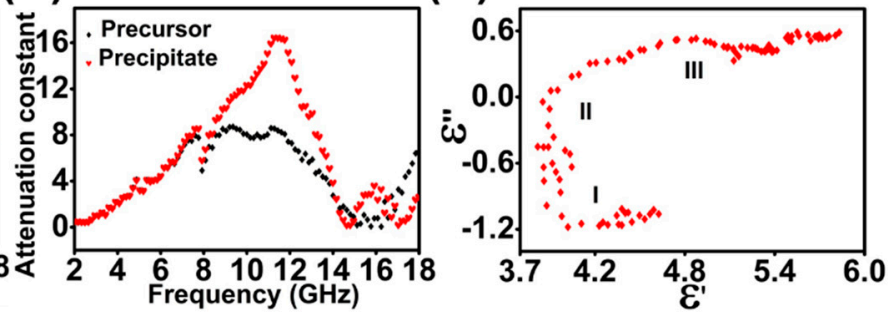

(D)

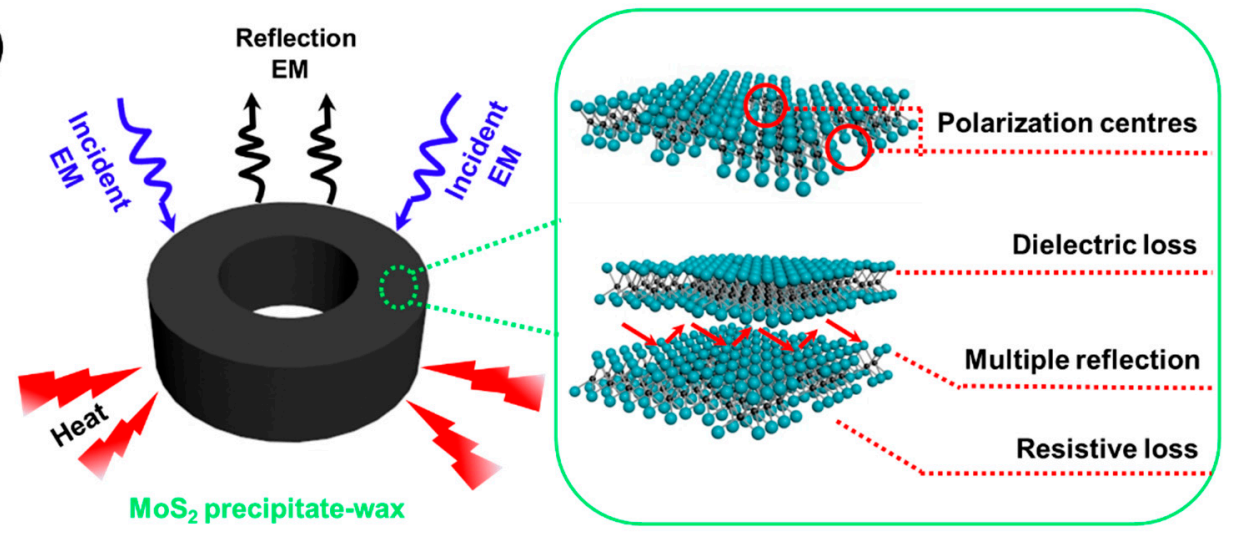

Figure 6. $\mathrm{Z}$ ratios (A) and $\alpha(\mathbf{B})$ of $\mathrm{MoS}_{2}$ precursor-wax composites and $\mathrm{MoS}_{2}$ precipitate-wax composites. (C) Cole-Cole plots for $\mathrm{MoS}_{2}$ precipitate-wax composites. (D) The mechanism of high EM wave absorption efficiency based on the $\mathrm{MoS}_{2}$ precipitate.

The real parts of complex permittivity $\left(\varepsilon^{\prime}\right)$ and imaginary parts $\left(\varepsilon^{\prime \prime}\right)$ stand for the storage and the loss capability of electromagnetic energy, respectively. As can be seen from Figure 5C,D, the $\varepsilon$ ' and $\varepsilon^{\prime \prime}$ of the two samples have similar trends with the change of frequency and the values of $\varepsilon$ ' and $\varepsilon^{\prime \prime}$ for $\mathrm{MoS}_{2}$ precursor-wax composites are slightly smaller than $\mathrm{MoS}_{2}$ precipitate-wax composites. The values $\varepsilon$ ' and $\varepsilon^{\prime \prime}$ are found to descend with the rising of frequency in the 2.0-13.0 GHz. Resulting from the lack of magnetism for the two samples, the real part $(\mu \prime)$ and the imaginary part $\left(\mu^{\prime \prime}\right)$ of the complex permeability was independent of the frequency, and remain 1 and 0 , respectively.

There are two key factors to evaluate an excellent absorber. One is the impedance matching $\left(Z=\left|Z_{\text {in }} / Z_{0}\right|\right)$, which requires the equality of the electromagnetic parameters based on Equation (2). When $\left|Z_{\text {in }} / Z_{0}\right|$ is close to 1 , the EMW could enter into the absorber with greater ease, instead of reflecting into the air, and then the optimal absorption performance can be achieved. The other is the EMW attenuation constant $(\alpha)$ in the interior of the absorber, the larger the value, the more electromagnetic energy is absorbed. The values of $\alpha$ determining the attenuation properties of materials and can be denoted by [50]

$$
\alpha=\frac{\sqrt{2} \pi f}{c} \times \sqrt{\left(\mu^{\prime \prime} \varepsilon^{\prime \prime}-\mu^{\prime} \varepsilon^{\prime}\right)+\sqrt{\left(\mu^{\prime \prime} \varepsilon^{\prime \prime}-\mu^{\prime} \varepsilon^{\prime}\right)^{2}+\left(\mu^{\prime} \varepsilon^{\prime \prime}+\mu^{\prime \prime} \varepsilon^{\prime}\right)^{2}}},
$$

Figure $6 \mathrm{~A}$ gives the frequency dependence of $Z=\left|Z_{\text {in }} / Z_{0}\right|$ and $\alpha$ values for $\operatorname{MoS}_{2}$ precipitate-wax composites and $\mathrm{MoS}_{2}$ precursor-wax composites in the frequency range between 2.0 and $18.0 \mathrm{GHz}$. As can be seen from Figure $6 \mathrm{~A}, \mathrm{Z}$ of $\mathrm{MoS}_{2}$ precipitate-wax composites are closer to 1 . It shows that the $Z$ characteristic of the $\mathrm{MoS}_{2}$ precipitate-wax composites is better than $\mathrm{MoS}_{2}$ precursor-wax composites, which means that the EMW is easier to enter the absorber of $\mathrm{MoS}_{2}$ precipitate-wax composites. Figure 6B exhibits the frequency dependence of the $\alpha$ in the range of 2.0-18.0 GHz. The $\mathrm{MoS}_{2}$ precipitate-wax composites have larger $\alpha$ values in the frequency range of $8.2-14.3 \mathrm{GHz}$, which means compared with $\mathrm{MoS}_{2}$ precursor-wax composites more EMW energy is absorbed for 
$\mathrm{MoS}_{2}$ precipitate-wax composites. Therefore, due to the good $Z$ and high $\alpha, \operatorname{MoS}_{2}$ precipitate have better electromagnetic absorption properties than that of $\mathrm{MoS}_{2}$ precursor.

Based on the Debye theory, $\varepsilon^{\prime}$ and $\varepsilon^{\prime \prime}$ can be described as [15]

$$
\begin{gathered}
\varepsilon^{\prime}=\varepsilon_{\infty}+\frac{\varepsilon_{\mathrm{S}}-\varepsilon_{\infty}}{1+\omega^{2} \tau^{2}}, \\
\varepsilon^{\prime \prime}=\frac{\varepsilon_{\mathrm{S}}-\varepsilon_{\infty}}{1+\omega^{2} \tau^{2}} \omega \tau+\frac{\sigma}{\omega \varepsilon_{0}},
\end{gathered}
$$

where $\omega$ is angular frequency, $\tau$ is polarization relaxation time, $\varepsilon_{\mathrm{s}}$ is static permittivity, $\varepsilon_{\infty}$ is relative dielectric permittivity at high-frequency limit and $\sigma$ is electrical conductivity. From the Debye theory Equation (4), we can conclude that with increasing of frequency the $\varepsilon$ ' value would be decreased, and that is consistent with the results of Figure 5C [51]. Equation (5) shows that $\varepsilon^{\prime \prime}$ is depended on the polarization and $\sigma$.

When the second part of the Equation (4) is not considered, the connection between $\varepsilon$ ' and $\varepsilon^{\prime \prime}$ can be described as

$$
\left(\varepsilon \prime-\frac{\varepsilon_{\mathrm{S}}+\varepsilon_{\infty}}{2}\right)^{2}+\left(\varepsilon^{\prime \prime}\right)^{2}=\left(\frac{\varepsilon_{\mathrm{S}}-\varepsilon_{\infty}}{2}\right),
$$

The Equation (6) represents to a circle centered at $\left(\left(\varepsilon_{\mathrm{S}}+\varepsilon_{\infty}\right) / 2,0\right)$, and every section of the arc form corresponds a Debye relaxation process. Figure 6C indicates the relationship of $\varepsilon$ ' between $\varepsilon^{\prime \prime}$ for $\mathrm{MoS}_{2}$ precipitate-wax composites in the frequency range of $2.0-18.0 \mathrm{GHz}$, and three clear semicircles can be obtained, which indicated that three Debye dipolar relaxation processes benefited to the dielectric loss mechanism for the $\mathrm{MoS}_{2}$ precipitate-wax composites [52].

The mechanism of excellent EM wave absorption property for the $\mathrm{MoS}_{2}$ precipitate was should be due to the following reasons (Figure 6D). Compared with $\mathrm{MoS}_{2}$ precursor material, $\mathrm{MoS}_{2}$ precipitate exhibits excellent and enhanced EMW attenuation capability, which results from good $Z$ and high $\alpha$. The good $\mathrm{Z}$ comes from the increasing of the amount of $\mathrm{MoS}_{2}$ nanosheets after electrolysis. The high $\alpha$ derives from the enhanced dielectric loss, which mainly caused by the increased polarization relaxation. When EMW propagates into the $\mathrm{MoS}_{2}$ precipitate-wax composites, some electrons could hop across the defects and the interface, which could contribute to the dielectric loss [8]. The enhanced dipolar polarization is enhanced by the increased surface point defects. After electrolysis, $\mathrm{MoS}_{2} \mathrm{QDs}$ are formed and peel off from the $\mathrm{MoS}_{2}$ precursor, and plentiful QDs cavities on the surface and edge of $\mathrm{MoS}_{2}$ were formed. The point defects could act as polarization centers under an alternating electric field. The interfacial polarization was enhanced, too, which mainly originates from the interface generated by the increased $\mathrm{MoS}_{2}$ layers. Also, due to the phase variation from $2 \mathrm{H} \mathrm{MoS} 2$ to $1 \mathrm{~T} \mathrm{MoS}$ in the process of electrolysis, the existed high conductivity of $1 \mathrm{~T} \mathrm{MoS}$ in the $\mathrm{MoS}_{2}$ precipitate composites has a positive contribution, that is enhanced resistive loss, towards EMW energy attenuation. The efficient EMW performance of the precipitate not only suggested the great application potential of the by-product of the $\mathrm{MoS}_{2}$ QDs, but also gave indirect evidence of the defects and phase variation generated during the BPE process.

\section{Conclusions}

In summary, a low cytotoxicity, simple, and nondestructive BPE electrochemical method has been developed to synthesize $\mathrm{MoS}_{2}$ QDs with a narrow size distribution and excellent aqueous solubility. Meanwhile, $\mathrm{MoS}_{2}$ nanosheets could also be observed in the electrolyzed precipitate, which showed excellent electromagnetic absorption performance. The BPE electrochemical process was not limited with the shape of the $\mathrm{MoS}_{2}$ precursor and could lead to the defects and phase variation of the $\mathrm{MoS}_{2}$ precursor, finally resulting in the as-prepared QDs and nanosheets. The advantages of this work can be summarized as follows. Firstly, $\mathrm{MoS}_{2}$ QDs was produced via simple, one-step top-down method, which is relatively low-cost and environmentally friendly due to the simple electrochemical instrument and low cytotoxicity PBS electrolyte. Secondly, the as-prepared $\mathrm{MoS}_{2}$ QDs is hydrosoluble, 
has low cytotoxicity, and is confirmed to be a promising alternative in PL staining and cell imaging. Furthermore, due to the defects and the phase transformation of the $\mathrm{MoS}_{2}$ deduced in the EC process, the as-produced precipitates containing the $\mathrm{MoS}_{2}$ nanosheets are highly efficient as an EMW absorber with its strong RL value and broad bandwidth absorption. The BPE design provides a versatile approach to prepare 2D layered nanomaterials in a convenient way. This work would widen the applicability of both the electrochemical methods and the 2D micro-/nano- materials.

Supplementary Materials: The following are available online at http://www.mdpi.com/2079-4991/9/6/906/s1, Figure S1: FL emission spectra with various excitation wavelengths of the supernatant under different peeling conditions. (A) $0.2 \mathrm{M} \mathrm{NH}_{4} \mathrm{~F}, 5 \mathrm{~V}, 20 \mathrm{~h}$; (B) $0.2 \mathrm{M} \mathrm{H}_{2} \mathrm{SO}_{4}, 5 \mathrm{~V}, 20 \mathrm{~h}$; (C) $0.2 \mathrm{M} \mathrm{PBS}$ (pH = 7.4), $3 \mathrm{~V}, 20 \mathrm{~h}$; (D) $0.2 \mathrm{M}$ PBS (pH = 7.4), $7 \mathrm{~V}, 20 \mathrm{~h}$; (E) 0.2 M PBS (pH = 7.4), $5 \mathrm{~V}, 10 \mathrm{~h}$; (F) $0.2 \mathrm{M} \mathrm{PBS} \mathrm{(pH=7.4),} 5 \mathrm{~V}, 30$ h. Figure S2: XPS spectra of the $S 2 p$ peak regions of $\mathrm{MoS}_{2}$ precursor (above) and $\mathrm{MoS}_{2}$ precipitate (below) samples. Figure S3: (A) Bright-field and (B-D) fluorescent images of cotton fiber stained with $\mathrm{MoS}_{2}$ QDs. The fluorescent images were obtained at the excitation wavelengths of (B) $510-550 \mathrm{~nm}$, (C) 330-385 nm, (D) $450-480 \mathrm{~nm}$. Scale bar: $50 \mathrm{~mm}$. Table S1: To further elucidate the novelty of this work, comparison of previous works with this one.

Author Contributions: Conceptualization, Y.X.; Data curation, Y.L. and X.W.; Formal analysis, Y.L. and X.W.; Investigation, Y.L.; Methodology, Y.L., M.L., and Y.X.; Project administration, M.L. and Y.X.; Resources, X.W., H.L., L.D., L.H., S.W., and C.Z.; Supervision, Y.X.; Validation, Y.L.; Writing-original draft, Y.L., and X.W.; Writing-review \& editing, Y.L. and Y.X.

Funding: This work was supported by the National Nature Science Foundation of China (nos. 21575071 and 21874079), Nature Science Foundation for Outstanding Young Scientists of Shandong Province (ZR2018JL011), Science \& Technology Fund Planning Project of Shandong Colleges and Universities (J16LA13), Qingdao Science \& Technology Planning Project (17-6-3-15-gx).

Conflicts of Interest: The authors declare no conflict of interest.

\section{References}

1. Pavlović, S.; Peeters, F.M. Electronic properties of triangular and hexagonal $\mathrm{MoS}_{2}$ quantum dots. Phys. Rev. B 2015, 91, 155410. [CrossRef]

2. Wang, X.; Wu, Q.; Jiang, K.; Wang, C.; Zhang, C. One-step synthesis of water-soluble and highly fluorescent $\mathrm{MoS}_{2}$ quantum dots for detection of hydrogen peroxide and glucose. Sens. Actuators B Chem. 2017, 252, 183-190. [CrossRef]

3. Lee, Y.H.; Zhang, X.Q.; Zhang, W.; Chang, M.T.; Lin, C.T.; Chang, K.D.; Yu, Y.C.; Wang, J.T.W.; Chang, C.S.; Li, L.J.; et al. Synthesis of large-area $\mathrm{MoS}_{2}$ atomic layers with chemical vapor deposition. Adv. Mater. 2012, 24, 2320-2325. [CrossRef] [PubMed]

4. Zhang, G.; Liu, H.; Qu, J.; Li, J. Two-dimensional layered $\mathrm{MoS}_{2}$ : Rational design, properties and electrochemical applications. Energy Environ. Sci. 2016, 4, 1190-1209. [CrossRef]

5. Huang, L.B.; Zhao, L.; Zhang, Y.; Chen, Y.Y.; Zhang, Q.H.; Luo, H.; Zhang, X.; Tang, T.; Gu, L.; Hu, J.S. Self-limited on-site conversion of $\mathrm{MoO}_{3}$ nanodots into vertically aligned ultrasmall monolayer $\mathrm{MoS}_{2}$ for efficient hydrogen evolution. Adv. Energy Mater. 2018, 8, 1800734. [CrossRef]

6. Yan, Y.; Xia, B.; Xu, Z.; Wang, X. Recent development of molybdenum sulfides as advanced electrocatalysts for hydrogen evolution reaction. ACS Catal. 2014, 4, 1693-1705. [CrossRef]

7. Liang, X.; Zhang, X.; Liu, W.; Tang, D.; Zhang, B.; Ji, G. A simple hydrothermal process to grow $\mathrm{MoS}_{2}$ nanosheets with excellent dielectric loss and microwave absorption performance. J. Mater. Chem. C 2016, 4, 6816-6821. [CrossRef]

8. Li, B.L.; Chen, L.X.; Zou, H.L.; Lei, J.L.; Luo, H.Q.; Li, N.B. Electrochemically induced Fenton reaction of few-layer $\mathrm{MoS}_{2}$ nanosheets: Preparation of luminescent quantum dots via a transition of nanoporous morphology. Nanoscale 2014, 6, 9831-9838. [CrossRef] [PubMed]

9. Ning, M.Q.; Lu, M.M.; Li, J.B.; Chen, Z.; Dou, Y.K.; Wang, C.Z.; Rehman, F.; Cao, M.S.; Jin, H.B. Two-dimensional nanosheets of $\mathrm{MoS}_{2}$ : A promising material with high dielectric properties and microwave absorption performance. Nanoscale 2015, 7, 15734-15740. [CrossRef]

10. Xu, G.; Wang, X.; Sun, Y.; Chen, X.; Zheng, J.; Sun, L.; Jiao, L.; Li, J. Metallic and ferromagnetic MoS $_{2}$ nanobelts with vertically aligned edges. Nano Res. 2015, 9, 2946-2953. [CrossRef]

11. Lin, H.; Wang, C.; Wu, J.; Xu, Z.; Huang, Y.; Zhang, C. Colloidal synthesis of $\mathrm{MoS}_{2}$ quantum dots: Size-dependent tunable photoluminescence and bioimaging. New J. Chem. 2015, 39, 8492-8497. [CrossRef] 
12. Zhu, H.; Zhang, H.; Xia, Y. Monodisperse three-layered $\mathrm{MoS}_{2}$ quantum dots as fluorescent reporters for 2,4,6-trinitrotoluene sensing in environmental water and luggage cases. Anal. Chem. 2018, 90, 3942-3949. [CrossRef] [PubMed]

13. Gopalakrishnan, D.; Damien, D.; Shaijumon, M.M. $\mathrm{MoS}_{2}$ quantum dot-interspersed exfoliated $\mathrm{MoS}_{2}$ nanosheets. ACS Nano 2014, 8, 5297-5303. [CrossRef] [PubMed]

14. Wang, Q.; Li, J. Facilitated lithium storage in $\mathrm{MoS}_{2}$ overlayers supported on coaxial carbon nanotubes. J. Phys. Chem. C 2007, 4, 1675-1682. [CrossRef]

15. Wu, F.; Xie, A.; Sun, M.; Wang, Y.; Wang, M. Reduced graphene oxide (RGO) modified spongelike polypyrrole (PPy) aerogel for excellent electromagnetic absorption. J. Mater. Chem. A 2015, 3, 14358-14369. [CrossRef]

16. Dong, H.; Tang, S.; Hao, Y.; Yu, H.; Dai, W.; Zhao, G.; Cao, Y.; Lu, H.; Zhang, X.; Ju, H. Fluorescent MoS 2 quantum dots: Ultrasonic preparation, up-conversion and down-conversion bioimaging, and photodynamic therapy. ACS Appl. Mater. Inter. 2016, 8, 3107-3114. [CrossRef] [PubMed]

17. Arul, N.S.; Nithya, V.D. Molybdenum disulfide quantum dots: Synthesis and applications. RSC Adv. 2016, 6, 65670-65682. [CrossRef]

18. Leong, S.X.; Mayorga-Martinez, C.C.; Chia, X.; Luxa, J.; Sofer, Z.; Pumera, M. 2H $\rightarrow 1$ T phase change in direct synthesis of $\mathrm{WS}_{2}$ nanosheets via solution-based electrochemical exfoliation and their catalytic properties. ACS Appl. Mater. Inter. 2017, 9, 26350-26356. [CrossRef]

19. Gui, R.; Jin, H.; Wang, Z.; Li, J. Black phosphorus quantum dots: Synthesis, properties, functionalized modification and applications. J. Chem. Soc. Rev. 2018, 47, 6795-6823. [CrossRef]

20. Mayorga-Martinez, C.C.; Khezri, B.; Eng, A.Y.S.; Sofer, Z.; Ulbrich, P.; Pumera, M. Bipolar electrochemical synthesis of $\mathrm{WS}_{2}$ nanoparticles and their application in magneto-immunosandwich assay. Adv. Funct. Mater. 2016, 26, 4094-4098. [CrossRef]

21. Liu, H.; Ye, T.; Mao, C. Fluorescent carbon nanoparticles derived from candle soot. Angew. Chem. 2007, 119, 6593-6595. [CrossRef]

22. Huang, H.; Du, C.; Shi, H.; Feng, X.; Li, J.; Tan, Y.; Song, W. Water-soluble monolayer molybdenum disulfide quantum dots with upconversion fluorescence. Part. Part. Syst. Charact. 2015, 32, 72-79. [CrossRef]

23. Liu, Y.; Nan, H.; Wu, X.; Pan, W.; Wang, W.; Bai, J.; Zhao, W.; Sun, L.; Wang, X.; Ni, Z. Layer-by-layer thinning of $\mathrm{MoS}_{2}$ by plasma. ACS Nano 2013, 7, 4202. [CrossRef]

24. Wang, Y.; Ni, Y. Molybdenum disulfide quantum dots as a photoluminescence sensing platform for 2,4,6-trinitrophenol detection. Anal. Chem. 2014, 86, 7463-7470. [CrossRef] [PubMed]

25. Hinnemann, B.; Moses, P.G.; Bonde, J.; Jørgensen, K.P.; Nielsen, J.H.; Horch, S.; Chorkendorff, I.; Nørskov, J.K. Biomimetic hydrogen evolution: $\mathrm{MoS}_{2}$ nanoparticles as catalyst for hydrogen evolution. J. Am. Chem. Soc. 2005, 127, 5308-5309. [CrossRef] [PubMed]

26. Melhuish, W.H. A standard fluorescence spectrum for calibrating spectro-fluorophotometers. J. Phys. Chem. 1961, 65, 229-235. [CrossRef]

27. Vadivelmurugan, A.; Anbazhagan, R.; Tsai, H.C. Preparation of fluorescent $\mathrm{MoS}_{2}$ quantum dots conjugated with various ligands, and its fluorescence imaging. Mater. Lett. 2018, 218, 285-289. [CrossRef]

28. Lee, C.; Yan, H.; Brus, L.E.; Heinz, T.F.; Hone, J.; Ryu, S. Anomalous lattice vibrations of single- and few-layer $\mathrm{MoS}_{2}$. ACS Nano 2010, 4, 2695-2700. [CrossRef]

29. Li, H.; Wu, J.; Yin, Z.; Zhang, H. Preparation and applications of mechanically exfoliated single-layer and multilayer $\mathrm{MoS}_{2}$ and $\mathrm{WSe}_{2}$ nanosheets. Acc. Chem. Res. 2014, 47, 1067-1075. [CrossRef]

30. Zhao, M.; Chen, A.Y.; Huang, D.; Chai, Y.Q.; Zhuo, Y.; Yuan, R. MoS 2 quantum dots as new electrochemiluminescence emitters for ultrasensitive bioanalysis of lipopolysaccharide. Anal. Chem. 2017, 89, 8335-8342. [CrossRef]

31. Li, H.; Chen, S.; Jia, X.; Xu, B.; Lin, H.; Yang, H.; Song, L.; Wang, X. Amorphous nickel-cobalt complexes hybridized with 1T-phase molybdenum disulfide via hydrazine-induced phase transformation for water splitting. Nat. Commun. 2017, 8, 15377. [CrossRef] [PubMed]

32. Joensen, P.; Frindt, R.F.; Morrison, S.R. Single-layer MoS 2 . Mater. Res. Bull. 1986, 21, 457-461. [CrossRef]

33. Bai, R.; Wang, P.; Fang, Y. Probing microstructures of molybdenum disulfide quantum dots by resonant Raman scattering. Appl. Phys. Lett. 2017, 110, 161910. [CrossRef]

34. Molina-Sánchez, A.; Wirtz, L. Phonons in single-layer and few-layer $\mathrm{MoS}_{2}$ and $\mathrm{WS}_{2}$. Phys. Rev. B 2011, 84, 155413. [CrossRef] 
35. Ha, H.D.; Han, D.J.; Choi, J.S.; Park, M.; Seo, T.S. Dual role of blue luminescent MoS $_{2}$ quantum dots in fluorescence resonance energy transfer phenomenon. Small 2014, 10, 3858-3862. [CrossRef] [PubMed]

36. Gu, W.; Yan, Y.; Cao, X.; Zhang, C.; Ding, C.; Xian, Y. A facile and one-step ethanol-thermal synthesis of $\mathrm{MoS}_{2}$ quantum dots for two-photon fluorescence imaging. J. Mater. Chem. B 2016, 4, 27-31. [CrossRef]

37. Mouri, S.; Miyauchi, Y.; Matsuda, K. Tunable photoluminescence of monolayer $\mathrm{MoS}_{2}$ via chemical doping. Nano Lett. 2013, 13, 5944-5948. [CrossRef] [PubMed]

38. Li, H.; Lu, G.; Yin, Z.; He, Q.; Li, H.; Zhang, Q.; Zhang, H. Optical identification of single- and few-layer $\mathrm{MoS}_{2}$ sheets. Small 2012, 8, 682-686. [CrossRef]

39. Clark, R.M.; Carey, B.J.; Daeneke, T.; Atkin, P.; Bhaskaran, M.P.; Latham, K.; Cole, I.S.; Kalantar-zadeh, K. Two-step synthesis of luminescent $\mathrm{MoS}_{2}-\mathrm{ZnS}$ hybrid quantum dots. Nanoscale 2015, 7, 16763. [CrossRef]

40. Lin, Y.C.; Dumcenco, D.O.; Huang, Y.S.; Suenaga, K. Atomic mechanism of the semiconducting-to-metallic phase transition in single-layered $\mathrm{MoS}_{2}$. Nat. Nanotechnol. 2014, 9, 391. [CrossRef]

41. Wang, Y.; Wang, S.; Li, C.; Qian, M.; Bu, J.; Wang, J.; Huang, R. Facile growth of well-dispersed and ultra-small $\mathrm{MoS}_{2}$ nanodots in ordered mesoporous silica nanoparticles. Chem. Commun. 2016, 52, 10217-10220. [CrossRef] [PubMed]

42. Ren, X.; Pang, L.; Zhang, Y.; Ren, X.; Fan, H.; Liu, S. One-step hydrothermal synthesis of monolayer $\mathrm{MoS}_{2}$ quantum dots for highly efficient electrocatalytic hydrogen evolution. J. Mater. Chem. A 2015, 3, 10693. [CrossRef]

43. Xiao, S.J.; Zhao, X.J.; Zuo, J.; Huang, H.Q.; Zhang, L. Highly photoluminescent $\mathrm{MoO}_{\mathrm{x}}$ quantum dots: Facile synthesis and application in off-on Pi sensing in lake water samples. Anal. Chim. Acta 2016, 906, 148-155. [CrossRef] [PubMed]

44. Štengl, V.; Henych, J. Strongly luminescent monolayered $\mathrm{MoS}_{2}$ prepared by effective ultrasound exfoliation. Nanoscale 2013, 5, 3387-3394. [CrossRef] [PubMed]

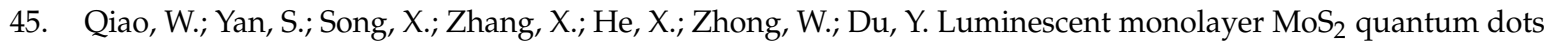
produced by multi-exfoliation based on lithium intercalation. Appl. Surf. Sci. 2015, 359, 130-136. [CrossRef]

46. Zhou, K.; Zhang, Y.; Xia, Z.; Wei, W. As-prepared $\mathrm{MoS}_{2}$ quantum dot as a facile fluorescent probe for long-term tracing of live cells. Nanotechnology 2016, 27, 275101. [CrossRef]

47. Shi, W.; Li, X.; Ma, H. A tunable ratiometric $\mathrm{pH}$ sensor based on carbon nanodots for the quantitative measurement of the intracellular $\mathrm{pH}$ of whole cells. Angew. Chem. 2012, 51, 6432-6435. [CrossRef]

48. Naito, Y.; Suetake, K. Application of ferrite to electromagnetic wave absorber and its characteristics. IEEE Trans. Microw. Theory 1971, 19, 65-72. [CrossRef]

49. Zheng, Y.; Wang, X.; Wei, S.; Zhang, B.; Yu, M.; Zhao, W.; Liu, J. Fabrication of porous graphene-Fe ${ }_{3} \mathrm{O}_{4}$ hybrid composites with outstanding microwave absorption performance. Compos. Part A Appl. Sci. 2017, 95, $237-247$. [CrossRef]

50. Xiang, J.; Li, J.; Zhang, X.; Ye, Q.; Xu, J.; Shen, X. Magnetic carbon nanofibers containing uniformly dispersed $\mathrm{Fe} / \mathrm{Co} / \mathrm{Ni}$ nanoparticles as stable and high-performance electromagnetic wave absorbers. J. Mater. Chem. A 2014, 2, 16905-16914. [CrossRef]

51. Wen, B.; Cao, M.S.; Hou, Z.L.; Song, W.L.; Zhang, L.; Lu, M.M.; Jin, H.B.; Fang, X.Y.; Wang, W.Z.; Yuan, J. Temperature dependent microwave attenuation behavior for carbon-nanotube/silica composites. Carbon 2013, 65, 124-139. [CrossRef]

52. Zhang, X.; Ji, G.; Liu, W.; Quan, B.; Liang, X.; Shang, C.; Cheng, Y.; Du, Y. Thermal conversion of an $\mathrm{Fe}_{3} \mathrm{O}_{4} @$ metal-organic framework: A new method for an efficient $\mathrm{Fe}-\mathrm{Co} /$ nanoporous carbon microwave absorbing material. Nanoscale 2015, 7, 12932-12942. [CrossRef] [PubMed]

(C) 2019 by the authors. Licensee MDPI, Basel, Switzerland. This article is an open access article distributed under the terms and conditions of the Creative Commons Attribution (CC BY) license (http://creativecommons.org/licenses/by/4.0/). 